\author{
JULIUSZ PIWOWARSKI \\ ORCID: 0000-0002-9196-1194 \\ Wyższa Szkoła Bezpieczeństwa Publicznego i Indywidualnego „Apeiron” w Krakowie \\ rektor@apeiron.edu.pl

\section{ŁUKASZ TRZCIŃSKI} \\ ORCID: 0000-0002-3014-1280 \\ Wyższa Szkoła Bezpieczeństwa Publicznego i Indywidualnego „Apeiron” w Krakowie \\ lukasztrzcinski@agh.edu.pl
}

\title{
Metodologiczna tożsamość antropologii bezpieczeństwa. Prolegomena
}

https://doi.org/10.19195/2083-7763.10.3

\begin{abstract}
Abstrakt
Całkowite bezpieczeństwo człowieka jest wyjątkowym stanem, ponieważ w dalszym ciągu dzielimy z innymi gatunkami podstawowe cechy ukształtowane w ciągu historii naturalnej. Wyjątkowość ludzkości wynika jednak z tworzenia przez nią szeroko rozumianej kultury. Powstający nurt antropologii bezpieczeństwa, ma związki z badaniami nad kulturą przez antropologię fizyczną, filozoficzną czy religijną, ale głównie jest on związany z antropologią społeczno-kulturową, co implikuje potrzebę włączenia w nią elementów kulturoznawczych. Odnosząc się z kolei do filozoficznych podstaw kwestii dotyczących bezpieczeństwa, antropolog bezpieczeństwa powinien koncentrować się na antropologicznych i kulturoznawczych aspektach dążeń ukierunkowanych na uzyskiwanie stanu wolności od zagrożeń. Tym samym obszarem badań dla antroposekuritologicznego nurtu nauki, który może być interpretowany jako subdyscyplina nauk o bezpieczeństwie, jest de facto całe spektrum elementów kultury bezpieczeństwa. Kultura bezpieczeństwa stanowi zjawisko występujące w całym obszarze ogromnego dorobku kultury ludzkiej, towarzyszące rozwojowi człowieka od zarania jego dziejów bez względu na to, czy w danym kontekście kulturowo-czasowo-przestrzennym ma tego świadomość, czy też kreuje to zjawisko i jego funkcjonowanie w sposób intencjonalny.
\end{abstract}

Słowa kluczowe: kultura bezpieczeństwa, antropologia, sekuritologia, bezpieczeństwo

W świetle teorii ewolucji bezpieczeństwo każdego z gatunków żyjących na Ziemi jest bardzo trudne do zrealizowania w perspektywie dłuższego czasu. Wynika 
to z faktu, że zasadniczym sposobem utrzymania się przy życiu oraz metodą rozprzestrzeniania życia, przyjmującą zasadniczo formę propagacji genów, jest walka o byt. Nie można zaś sobie wyobrazić walki bez włączenia w nią pojęcia zagrożenia. Podobnie jak geny konkurują między sobą o loci (miejsca) w genotypie, tak gatunki konkurują między sobą w określonym ekosystemie. Zakładając, że życie powstało na Ziemi około 4,1 mld lat temu, trzeba stwierdzić, że do naszych czasów — i to nie z powodu działalności człowieka - wyginęło w przybliżeniu 95\% gatunków istot żywych, które nie potrafiły się dostatecznie adaptować do zmieniającego się środowiska. Proces ten przyspieszył ostatnio z powodu włączenia sięludzkości w niszczycielską działalność wynikającą głównie z procesów gwałtownego uprzemysłowienia, niezważającą na ogół na konieczność współdziałania z szeroko rozumianym środowiskiem. Ostatnio pojawiła się jednak próba, w ramach różnych programów zrównoważonego rozwoju, sformułowania takiego podejścia do świata, które ma na celu zatrzymanie destrukcyjnej ekspansji naszego gatunku. W tej sytuacji człowiek stanowiący, jak zauważa Stanisław Jarmoszko, szczególny „organizm biologiczny i fenomen psychoruchowy, [który] nie może obyć się bez bezpieczeństwa"1, nie odbiega od innych gatunków, chociaż stosowane przez niego strategie różnią się od wszystkich dotychczas istniejących w świecie ożywionym.

$\mathrm{O}$ ile inne gatunki z reguły dostosowywały się do zmieniających się warunków, o tyle ludzkość, odkąd tylko człowiek pojawił się na Ziemi, stara się dostosować zewnętrzne uwarunkowania do siebie (co nie oznacza oczywiście, że sama się też nie zmienia). Podstawowym czynnikiem umożliwiającym taką transformację kierunków procesów przystosowawczych było pojawienie się samoświadomości (świadomości refleksyjnej), z którą antropologia wiąże powstanie cech specyficznie ludzkich. Oprócz świadomości refleksyjnej Homo sapiens określają jeszcze następujące cechy: pionizacja ciała z lokomocją dwunożną przy uwolnieniu rąk od czynności przemieszczania się, głowa o dużej pojemności, zaokrąglona i słabo urzeźbiona, ze zredukowaną twarzoczaszką, wszystkożerne uzębienie, brak okresu rui, najdłuższe okresy rozwoju osobniczego wśród prymatów, kontrola życia emocyjnego, podstawowy system komunikacji w postaci mowy artykułowanej, wytwarzanie kultury ${ }^{2}$. Wspomniana świadomość refleksyjna, czyli

\footnotetext{
${ }^{1}$ S. Jarmoszko, Antropologia bezpieczeństwa, Siedlce 2018, s. 27.

2 Te cechy człowieka formułuje przede wszystkim antropologia fizyczna (biologiczna). Antropologia to termin będący wynikiem złożenia dwóch greckich słów: äv $\theta \rho \omega \pi o \varsigma$, [anthropos] —

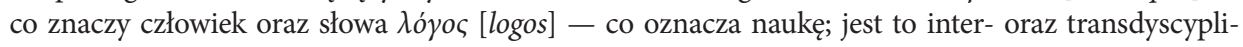
narna dyscyplina naukowo-badawcza włączająca elementy trychotomii, jaką tworzą nauki humanistyczne, nauki społeczne oraz nauki przyrodnicze. Jeśli chodzi o trzeci wymiar, to mimo że jej początki znajdziemy już w starożytnej Grecji w pismach Herodota, Hipokratesa i innych starożytnych uczonych, to jednak naukowe podstawy antropologii fizycznej (biologicznej) zostały opracowane dopiero w XIX wieku. Miało to miejsce w czasach aktywności naukowej francuskiego chirurga Pierre’a Paula Broca (1824-1880), który jako jeden z pierwszych określił funkcje, jakie ma pełnić w świecie nauki an tropolog ia i opracował dla niej metody. W roku 1859 założył on w Paryżu pierwsze Towarzystwo Antropologiczne, w 1872 pierwsze w świecie czasopismo antropologiczne
}

Forum Socjologiczne 10, 2020

(C) for this edition by CNS 
zdolność nakierowania swojej świadomości na nią samą, stała się podstawą myślenia abstrakcyjnego, a więc między innymi tworzenia modeli rzeczywistości oraz przewidywania na ich podstawie przyszłych zdarzeń. W kontekście zagadnień bezpieczeństwa trzeba jednak zauważyć, że nigdy takie modelowanie nie osiąga całkowitej doskonałości, przewidywania zaś sprawdzają się w bardzo ograniczonym zakresie ${ }^{3}$. Dlatego sytuacja żadnego człowieka, jak też żadnej tworzonej przez ludzi społeczności nie jest nigdy całkowicie pewna. Można by zaryzykować nawet stwierdzenie, że samo życie polega na nieustannym przeciwstawianiu się zagrożeniom. Jak zauważył antropolog kulturowy, filozof i muzyk rockowy Krzysztof J. Brozi (1952-1996), „stałą cząstką ludzkiego istnienia jest irracjonalna nadzieja osiągnięcia pełnego bezpieczeństwa"4 Abstrahując w tej chwili od określenia „irracjonalna nadzieja", trudno się nie zgodzić z tą wypowiedzią. Analogiczną myśl znaleźć możemy u amerykańskiego uczonego Clyde’a Kluckhohna, który przyczyny powstawania znanych z literatury antropologicznej setek mitów upatrywał $\mathrm{w}$ nieustannym poszukiwaniu poczucia bezpieczeństwa. Jak pisał:

Zarówno mit, jak i rytuał zapewniają kulturowe rozwiązanie problemów, z którymi stykają się wszyscy ludzie [...]. W obliczu niedostatku, śmierci i zniszczenia wszyscy ludzie odczuwają fundamentalny brak poczucia bezpieczeństwa. W pewnym stopniu cała kultura jest gigantycznym wysiłkiem, by to zamaskować, by dać przyszłości pozór bezpieczeństwa... ${ }^{5}$

Z systemowego punktu widzenia powyższe stwierdzenia zilustrować można, odwołując się do koncepcji inżyniera i informatyka profesora Ryszarda Tadeusiewicza, mówiącego o kolejnych budowanych przez ludzkość „kapsułach” zapewniających poczucie bezpieczeństwa. Jak pisze,

ludzie bowiem w toku swych dziejów wielokrotnie chowali się w głębi kolejnych powłok, swoistych kokonów, które oferowała im rozwijająca się cywilizacja" [...] wszystkie te ważne dla ludzi uwarunkowania tworzyły kolejne cywilizacyjne otoczki (kokony), w których ci ludzie się zagrzebywali, aby dzięki nim uniezależnić się od niedogodności zakłóceń porządku albo restrykcji, narzucanych przez zmienność otaczającego ich świata. Każdy z tych cywilizacyjnych kokonów chronił przed czymś z zewnątrz, ale jednocześnie wprowadzał ograniczenia dla tych, którzy znajdowali się w jego wnętrzu. Jeśli, przykładowo, potraktować jako taki kokon przejście od formy życia koczowniczego i gospodarki zbieracko-łowieckiej do życia osiadłego, związanego z budową domów, lepiej niż jaskinie i szałasy chroniących przed zmiennością pogody, wraz z gospodarką agrarną, lepiej chroniąca przed klęską głodu, do której wcześniej łatwo mogło

„Revue d’anthropologie”, w 1876 roku zaś powstała, także z inicjatywy P.P. Broki, pierwsza szkoła antropologiczna L'École d’antropologie de Paris.

${ }^{3}$ Noreena Hertz z Uniwersytetu w Cambridge podaje, iż analizy przeprowadzone przez P.E. Tetlocka z Princeton University wykazały, że „Badanie 82000 prognoz wykonanych przez 284 ekspertów w okresie szesnastu lat... pokazało, że znawcy absolutnie nie byli lepsi niż małpa na chybił trafił wtykająca szpilki w tablicę", N. Hertz, Oczy szeroko otwarte, przeł. J. Sawicka, Warszawa 2014, s. 84 .

${ }^{4}$ K.J. Brozi, Ludzie i kryzys cywilizacji. Szkice antropologiczne, Lublin 1995, s. 12.

${ }^{5}$ C. Kluckhohn, Myths and Rituals, a General Theory, [w:] Reader in Comparative Religion, Anthropological Approach, red. E. Lesa, Z. Vogt, New York, s. 147.

Forum Socjologiczne 10, 2020

(C) for this edition by CNS 
dojść wskutek niemożności upolowania wystarczającej liczby zwierzyny oraz zebrania odpowiedniej ilości płodów rolnych - to, jak się wydaje, zalety tego pierwszego cywilizacyjnego kokonu okupione były utratą swobody, którą gwarantowało życie koczownika ${ }^{6}$.

Współczesność związana jest także z poważną zmianą cywilizacyjną, z budowaniem nowego „kokonu”, chroniącego przed niebezpieczeństwami technosfery, ale jednocześnie ograniczającego dotychczasowe nietechnologiczne wymiary egzystencji. Ludzkość może wybrać, czy zgodnie z postulatami transhumanizmu pozwoli sobie na całkowite zanurzenie się (immersję) w infosferze, czy raczej starać się będzie w miarę możliwości zachować tradycyjny sposób egzystencji, określonej dotychczasowymi systemami wartości.

Całkowite bezpieczeństwo człowieka stanowi wyjątkowy stan, ponieważ w dalszym ciągu dzielimy $\mathrm{z}$ innymi gatunkami podstawowe cechy ukształtowane w ciągu historii naturalnej. Wyjątkowość ludzkości wynika jednak z tworzenia przez nią szeroko rozumianej kultury. Powstający nurt antropologii bezpieczeństwa ma związki z badaniami nad kulturą poprzez antropologię fizyczną, filozoficzną czy religijną, ale głównie jest on związany z antropologią społeczno-kulturową, co implikuje potrzebę włączenia w nią elementów kulturoznawczych. Odnosząc się z kolei do filozoficznych podstaw kwestii dotyczących bezpieczeństwa ${ }^{7}$, antropolog bezpieczeństwa powinien koncentrować się na antropologicznych i kulturoznawczych aspektach dążeń ukierunkowanych na uzyskiwanie stanu wolności od zagrożeń. Tym samym obszarem badań dla antroposekuritologicznego nurtu nauki, który może być interpretowany jako subdyscyplina nauk o bezpieczeństwie, jest de facto całe spektrum elementów kultury bezpieczeństwa. Kultura bezpieczeństwa stanowi zjawisko występujące w całym obszarze ogromnego dorobku kultury ludzkiej, towarzyszące rozwojowi człowieka od zawsze, bez względu na to, czy w danym kontekście kulturowo-czasowo-przestrzennym ma tego świadomość, czy też kreuje to zjawisko i jego funkcjonowanie w sposób intencjonalny.

W literaturze przedmiotu funkcjonuje kilka szerzej rozbudowanych określeń fenomenu kultury bezpieczeństwa. Należą do nich na przykład definicja Mariana Cieślarczyka ${ }^{8}$ czy nowe wzory kultury bezpieczeństwa ukazane przez Stani-

\footnotetext{
${ }^{6}$ R. Tadeusiewicz, Mity i rzeczywistość społeczeństwa informacyjnego, [w:] Mity współczesnej duchowości, red. Ł. Trzciński, Kraków 2010, s. 23.

${ }^{7}$ Konstruowanymi przez filozofię bezpieczeństwa - zob. R. Rosa, Filozofia bezpieczeństwa, Warszawa 1995; J. Świniarski, W. Chojnacki, Filozofia bezpieczeństwa. Podręcznik akademicki, Warszawa 2004; R. Rosa, M. Lipińska-Rzeszutck, M. Kubiak, Filozofia bezpieczeństwa personalnego i strukturalnego, Siedlce 2008; K. Kołodziejczyk, Filozofia bezpieczeństwa. Problemy aksjologiczne, Wrocław 2010.

${ }^{8}$ M. Cieślarczyk, Kultura bezpieczeństwa i obronności, Siedlce 2007, s. 210; idem, Fenomen bezpieczeństwa i zjawisko kryzysów postrzegane w perspektywie kulturowej, [w:] Jedność i różnorodność. Kultura vs. kultury, red. F. Rekłajtis, R. Wiśniewski, J. Zdanowski, Warszawa 2010, s. 85; por. A. Filipek, Poziom i charakter kultury bezpieczeństwa młodzieży akademickiej, Siedlce 2007.
}

Forum Socjologiczne 10, 2020

(C) for this edition by CNS 
sława Jarmoszkę ${ }^{9}$. Rozbudowana, spektralna wersja definicji kultury bezpieczeństwa, ukazująca wage świadomości podmiotu bezpieczeństwa ${ }^{10}$, została natomiast ujęta $\mathrm{w}$ definicji stworzonej przez Juliusza Piwowarskiego i Vasyla Zaplatynskiego ${ }^{11}$.

Przy tworzeniu zaawansowanej wersji definicji, aby ukazać oddziaływanie energii społecznej ${ }^{12}$, jaką gromadzi, stymuluje i której nadaje kierunek kultura bezpieczeństwa, inspiracją była pewna analogia do pojęć związanych z matematyczną teorią pola ${ }^{13}$. Oczywiście podobieństwa nie stanowią dowodu, ale mogą wzbudzać określone intuicje, które w konsekwencji stają się użyteczne.

Kultura bezpieczeństwa w prezentowanym tu ujęciu stanowi ogół utrwalonego, materialnego i pozamaterialnego dorobku człowieka służącego rozumianej szeroko, militarnie i niemilitarnie, autonomicznej obronności określonych indywidualnych oraz grupowych podmiotów. Kulturę bezpieczeństwa można określić jako pole oddziaływań społecznych. Nasuwa się tu trychotomia odzwierciedlająca się w tym polu:

1. strumień mentalno-duchowy (wymiar indywidualny),

2. strumień organizacyjno-prawny (wymiar społeczny),

3. strumień materialny.

Pole (oddziaływań) kultury bezpieczeństwa pozwala przebywającemu w sferze jego oddziaływań podmiotowi realizować następujące cele, związane z funkcją dążenia do wolności od zagrożeń:

1. Kontrola i panowanie nad niebezpieczeństwami celem uzyskania stanu satysfakcjonująco niskiego poziomu zagrożeń.

2. Odzyskiwanie bezpieczeństwa, gdy zostało ono obniżone lub w danym aspekcie utracone.

${ }^{9}$ S. Jarmoszko, Nowe wzory kultury bezpieczeństwa a proces deterioracji więzi społecznej, [w:] Jedność i różnorodność. Kultura vs kultury, red. E. Rekłajtis, R. Wiśniewski, J. Zdanowski., Warszawa 2010, s. 103 n.

${ }^{10}$ Por. A. Zduniak, N. Majchrzak, Świadomość emocjonalna jako dystraktor w procesach badawczych bezpieczeństwa, [w:] Metodologia badań bezpieczeństwa narodowego, t. 3, red. P. Sienkiewicz, M. Marszałek, H. Świeboda, Warszawa 2012.

${ }^{11}$ J. Piwowarski, Ochrona VIP-a a czworokąt bushido. Studium japońskiej kultury bezpieczeństwa, [w:] Bezpieczeństwo osób podlegających ustawowo ochronie wobec zagrożeń XXI wieku, red. P. Bogdalski, J. Cymerski, K. Jałoszyński, Szczytno 2014, s. 445-473.

12 S.H. Young, Social Energy, kwiecień 2007, http://www.scotthyoung.com/blog/2007/04/10/ social-energy/ (dostęp: 21.03.2019).

13 Polskiemu współtwórcy definicji chodziło o pewną analogię z pojęciem oddziaływania w przestrzeni pola wektorowego oraz ukierunkowanych strumieni pola. W fizyce pole wektorowe stanowi funkcję przyporządkowującą każdemu punktowi przestrzeni określoną wielkość wektorową. Idea pola wektorowego odwołuje się do teorii przestrzeni Hilberta. Narzędzie to stosuje się na przykład w mechanice kwantowej. Strumień pola pozwala opisać pole wektorowe oraz jego źródło. Definicja strumienia pola oddziaływań wydaje się spójna z jego intuicyjnym odbiorem. Badając oddziaływanie pola, należy oszacować moc reprezentujących to pole strumieni energii. Por. K. Maurin, Metody przestrzeni Hilberta, Warszawa, 1959; D. Halliday, R. Resnick, J. Walker, Podstawy Fizyki, t. 3, Warszawa 2003.

Forum Socjologiczne 10, 2020

(C) for this edition by CNS 
3. Optymalizacja wielosektorowo percypowanego bezpieczeństwa poprzez harmonijne, dostosowane do potrzeb proporcje rozwoju sektorów bezpieczeństwa.

4. Pobudzanie potrzeb harmonijnego rozwoju (mentalny/społeczny/materialny) oraz uaktywnianie motywacji i postaw skutkujących indywidualnym i kolektywnym działaniem odnośnie do rozwoju indywidualnych i grupowych podmiotów bezpieczeństwa.

Antropologia bezpieczeństwa obejmuje swymi badaniami ogół ludzkich dyspozycji i dokonań w zakresie możliwości kreacji warunków dających jednostkom i zbiorowościom społecznym szanse uzyskania bezpiecznej egzystencji i wysokiego prawdopodobieństwa przetrwania oraz swobody wieloaspektowego rozwoju.

W tym wypadku centralne kategorie to 1 . człowiek, 2. bezpieczeństwo oraz 3. kultura bezpieczeństwa, szczególnie w tym jej zakresie, który dotyczy, jak mówi Stanisław Jarmoszko, „określonych dyspozycji psychosomatycznych i behawioralnych, a także norm i wzorów ludzkich działań (tzw. kulturowych wzorów bezpieczeństwa) służących jego kreowaniu"14.

Sformułowanie dotyczące norm i wzorców ludzkich działań nasuwa na myśl dokonania szkoły kulturalistycznej (konfiguracjonizmu) w antropologii, reprezentowanej między innymi przez Ruth Benedict (1887-1948) oraz Ralpha Lintona (1893-1953). Benedict pisze, że wzory kulturowe stanowią „,różnorodne zachowania, nastawione na zdobywanie środków do życia, życie płciowe, prowadzenie wojen i kult bogów [i] przekształcają się w trwałe wzory zgodnie z nieświadomymi kanonami wyboru, które rozwijają się w obrębie danej kultury"15. Pozbawiając wzory kulturowe romantycznej otoczki, wynikającej często z niemieckich koncepcji „ducha narodu”, i sprowadzając te tematy do rzeczywistości empirycznej, można powiedzieć, że wzór kulturowy powstaje w miejscu i czasie, w których człowiek ma potrzebę systematycznego powtarzania określonej czynności, a aktywność ta jest dlań niezbędna do właściwego, a zatem i bezpiecznego prowadzenia swojej egzystencji.

W opinii amerykańskiego socjologa i antropologa Ralpha Lintona istnieje

potrzeba bezpieczeństwa i upewniania się [odzwierciedlająca] się w niezliczonych formach kulturowo uwzorowanych zachowań. To [właśnie] ona prowadzi do tego, że wytwórca w społeczeństwach pierwotnych wprowadza do swojej technologii magię, a człowiek z innych sfer kultury wyobraża sobie niebiosa, w których [kiedyś, po swojej śmierci] uzyska nagrodę za odpowiednie postępowanie za życia ${ }^{16}$.

W ten sposób powstaje kultura rzeczywista, którą badacz możne identyfikować jako konfigurację zbudowaną z wielości rozmaitych wzorów, w różnym stopniu dopasowujących się do siebie i co ważne - funkcjonalnie współzależnych. Badanie struktury utworzonej z takich wzorów nie jest sprawą łatwą, jednak nie wydaje się,

${ }^{14}$ S. Jarmoszko, Antropologia bezpieczeństwa..., s. 28.

${ }^{15}$ R. Benedict, Wzory kultury, przeł. J. Prokopiuk, Warszawa 2008, s. 108.

${ }^{16}$ R. Linton, Kulturowe podstawy osobowości, przeł. A. Jasińska-Kania, Warszawa 2000, s. 22. 
by takie działania nie poddawały się operacjonalizacji. Dlatego też posługiwanie się zmodyfikowanymi w pewien sposób i dostosowanymi do antropologii bezpieczeństwa koncepcjami konfiguracjonizmu wydaje się usprawiedliwione.

Na przykład S. Jarmoszko, w swoich pracach podkreśla, że „wzór kulturowy odnosi się $[\ldots]$ do ograniczonej skali ludzkich zachowań jako normalnych i efektywnych reakcji na konkretną sytuację życiową" ${ }^{\prime 17}$.

Skomplikowany ciąg dziejów ludzkiego istnienia i rozwoju łączy się nie tylko funkcjonalnie, lecz także organicznie z dziejami społecznego konstruowania, wdrażania i utrwalania wzorów kultury bezpieczeństwa. Odwołując się znowu do inspiracji czerpanej z myśli polskiego pioniera antropologii bezpieczeństwa, można powiedzieć jego słowami, że

wzory [kultury bezpieczeństwa można pojmować] [...] jako przyjęte w społeczeństwie (bądź tylko lokalnie w jego wyspecjalizowanych agendach) standardy zachowania i działania zmierzające do zapewnienia stanu bezpieczeństwa w odniesieniu do jego całości, poszczególnych środowisk, struktur i pojedynczych ludzi ${ }^{18}$.

Poprzez powtarzane działania tworzą się owe szczególne, utrwalone społecznie wzory kultury (bezpieczeństwa). Są to wzory myślowe i, idąc dalej, wzory dotyczące projektowania, metod planowania, działań o charakterze określonych realizacji, wzory bezpiecznego, perfekcyjnego komunikowania się oraz wzory skutecznych metod czy też sposobów przetwarzania informacji w powyższym zakresie, a także utrwalone formy mechanizmów oraz procedur profilaktycznych i bezpośredniej reakcji. Zgodnie z przyjętą strukturą kultury bezpieczeństwa zawierają one zarówno elementy materialne, organizacyjne, behawioralne, jak i duchowe, a także symboliczne. Kształtują się intersubiektywnie, ale stanowią swego rodzaju epifenomen każdej wspólnoty ${ }^{19}$. Jak twierdzi Jarmoszko:

Antropologia bezpieczeństwa orientuje się na naturalne dyspozycje (właściwości) ochronne i obronne człowieka (indywidualne i zbiorowe), ale przede wszystkim na wykreowane przez niego technologie budowania bezpieczeństwa oraz całokształt ludzkich wytworów (artefaktów) wynikających z ich stosowania ${ }^{20}$.

Patrząc na te kwestie z antropologicznej perspektywy, fenomen bezpieczeństwa jawi się badaczowi zarówno jako przestrzeń dostępna kreatywności indywidualnych i zbiorowych podmiotów bezpieczeństwa, jak i jednocześnie jako rezultat owej kreatywności. Jest zatem nie tyle ciągiem następujących po sobie stanów, tworzących obraz procesu o charakterze naturalnym, ile zjawiskiem, intencjonalnie kreowanym przez człowieka społecznym konstruktem. Stanowi on efekt

17 S. Jarmoszko, Antropologia bezpieczeństwa..., s. 28.

18 Ibidem.

19 Zob. Z. Staszczak, Wzór kulturowy, [w:] Słownik etnologiczny. Terminy ogólne, red. Z. Staszczak, Warszawa-Poznań 1987, s. 372-374; S. Jarmoszko, Nowe wzory kultury bezpieczeństwa a procesy deterioracji więzi społecznej, [w:] Jedność i różnorodność..., s. 101-114.

${ }^{20}$ S. Jarmoszko, Antropologia bezpieczeństwa..., s. 29. 
ludzkich intencji, towarzyszących im przemyśleń, a wreszcie - wytwór działania człowieka, rozpatrywany z punktu widzenia zagrożeń i bezpieczeństwa.

We Wstępie do Anthropology and Security Studies Fina Anton Hurtado i Giovanni Ercolani zaznaczają, że badając relacje pomiędzy antropologią bezpieczeństwa a studiami nad bezpieczeństwem, bezpieczeństwo można potraktować jako szczególną antropologiczną przestrzeń w szerokim znaczeniu tego słowa. Bezpieczeństwo w tym podejściu jest konceptem kulturowym, który z jednej strony określa się swoistym terminem, a $\mathrm{z}$ drugiej strony jest to pewne "terytorium” będące środowiskiem, w którym antropolog bezpieczeństwa powinien nie tylko interpretować zastaną rzeczywistość, ale także próbować ją pozytywnie kształtować ${ }^{21}$. Bezpieczeństwo staje się w świetle takiej interpretacji nie tylko wartością egzystencjalną, lecz także instrumentalną oraz poznawczą. Z pozycji antropologii socjo-kulturowej w zakresie dotyczącym pokrewnego dla nauk o bezpieczeństwie nurtu, jakim są studia nad bezpieczeństwem, możemy postawić tezę, że antropologia bezpieczeństwa ma bardzo duży potencjał badawczy. Metody stosowane dotychczas w antropologii przedstawiają się jako pomocne w odkrywaniu uwarunkowań ochronnej infrastruktury krytycznej, zagrożeń biologicznych, sposobów przeżycia w trudnych sytuacjach oraz cech profesjonalnych kompetencji w zakresie zapewniania bezpieczeństwa. Przedmiotem badań będą tu także różnice konceptualne. Można tu dodać, że często w polityce bezpieczeństwa i dyskursie dotyczącym tej wrażliwej sfery pojawia się ubóstwienie techniki, co bezkrytycznie jest eksponowane w security studies ${ }^{22}$.

Przedstawiciele security studies wskazują na ogół, że bezpieczeństwo odnosi się przede wszystkim do działania w trudnej sytuacji, sprowadzonego do alternatywy umrzeć albo przeżyć. Staje się to jaskrawo widoczne w strefach licznych konfliktów pojawiających się w świecie. Ponieważ ta alternatywa ogniskuje w sobie problemy z zakresu antropologii, reprezentanci security studies postulują, by bezpieczeństwo było przedmiotem coraz większego zainteresowania antropologów.

Dążąc do określenia ram przedmiotu badań dla antropologii bezpieczeństwa, należałoby jeszcze wskazać na typologię, jaką przedstawił Luis Alvarez Munarriz. Ten hiszpański antropolog społeczny identyfikuje cztery następujące płaszczyzny dotyczące problematyki antropologii bezpieczeństwa ${ }^{23}$ :

1. bezpieczeństwo konkretnego człowieka (indywidualny wymiar bezpieczeństwa),

2. bezpieczeństwo publiczne (społeczny wymiar bezpieczeństwa),

3. bezpieczeństwo [społeczno-]kulturowe (symboliczny wymiar bezpieczeństwa),

4. bezpieczeństwo geopolityczne (wymiar terytorialny bezpieczeństwa).

${ }^{21}$ F.A. Hurtado, G. Ercolani, Introduction. Anthropology and Security Studies, [w:] Anthropology and Security Studies, red. F.A. Hurtado, G. Ercolani, Nottingham 2013, s. 25 n.

${ }^{22}$ V.M. Maguire, C. Frois, N. Żurawski, Introduction. The Anthropology of Security: Prospects, Retrospects and Aims, [w:] The Anthropology of Security: Perspectwes front the Frontline of Policing, red. M. Maguire, C. Frois, N. Żurawski, London 2014, s. 9.

${ }^{23}$ L.A. Munarriz, Foreword. Anthropological Approach to Security, [w:] Anthropology and Security..., s. 5-14.

Forum Socjologiczne 10, 2020

(C) for this edition by CNS 
Munarriz określa bezpieczeństwo jako uniwersalną potrzebę dotyczącą człowieczeństwa oraz najbardziej cenne dobro społeczne. Rozpatrywane zaś jako termin, ma według tego badacza polisemantyczną istotę. Zgłębianie bezpieczeństwa wymaga więc multi- oraz transdyscyplinarnego podejścia naukowego.

Antropologia bezpieczeństwa sytuuje się na przecięciu dwóch sfer badawczych, dwóch dyscyplin, jakimi są antropologia i nauki o bezpieczeństwie. Specyfika obu tych nauk powoduje, że powstają określone wyzwania identyfikacyjne w odniesieniu do utworzonej z nich fuzji, jaką jest antropologia bezpieczeństwa. Owa fuzja tworzy $\mathrm{z}$ kolei szansę na skonstruowanie nowych ram dla jakże ważnego dla człowieka i w gruncie rzeczy nowatorskiego obszaru zainteresowań naukowo-badawczych. Jak zauważył S. Jarmoszko, „właściwe zdefiniowanie naukowej tożsamości antropologii bezpieczeństwa wymaga pełnego uświadomienia istoty jej nauk genetycznych"24.

Jeszcze raz przypomnijmy, czym jest antropologia. Zgodnie z szeroką definicją Wojciecha Burszty antropologia to najogólniejsza wiedza o człowieku jako o bycie $\mathrm{z}$ jednej strony uwikłanym $\mathrm{w}$ biologię, zaś z drugiej strony budującym swą kulturę na bazie siatki pojęciowej, odnosząca się do symbolicznych znaczeń, który istnieje „wśród ludzi i dla innych ludzi” ${ }^{25}$. Zaznaczona tu rozległość uwzględniać musi takie aspekty ludzkiego życia jak biologiczny, psychologiczny, teleologiczny, filozoficzny, teologiczny, społeczny, prakseologiczny lub kulturowy.

$\mathrm{Z}$ kolei nauki o bezpieczeństwie są dyscypliną, która dopiero niedawno została skategoryzowana (2011) w ramach dziedziny nauki (do niedawna obszaru nauki), jaką stanowią nauki społeczne. Jak wskazuje już sama nazwa, procedury badawcze podejmowane w naukach o bezpieczeństwie mają dotyczyć kwestii szeroko rozumianego fenomenu, jakim jest bezpieczeństwo. Ich tożsamość dopiero obecnie się kształtuje, dzięki dynamice, jaką zyskał dyskurs naukowy środowisk akademickich i tych gremiów, które skupiają osoby praktycznie zaangażowane w problematykę dotyczącą realizacji zadań na rzecz zapewniania „bezpieczeństwa". Kwestią podstawową staje się zatem to, w jaki sposób interpretujemy znaczenie terminu bezpieczeństwo.

米米

Prowadzone rozważania dobrze podsumowują słowa S. Jarmoszki, który zauważa, że

bezpieczeństwo staje się [...] przedmiotem zainteresowania antropologii, jako najbardziej ogólnej i całościowej nauki o człowieku, gdyż służy jego istnieniu i przetrwaniu, a zarazem jest owocem jego aktywności. W perspektywie antropologicznej bezpieczeństwo jawi się więc

${ }^{24}$ S. Jarmoszko, Antropologia bezpieczeństwa..., s. 30.

${ }^{25}$ W.J. Burszta, Wprowadzenie do wydania polskiego, [w:] F.C. Sałzman, P.C. Rice, Myśleć jak antropolog, Gdańsk 2009, s. 14.

Forum Socjologiczne 10, 2020

(C) for this edition by CNS 
jako przestrzeń kreacji, a zarazem rezultat owej kreacji. Bezpieczeństwo jest tu zatem nie tyle stanem/procesem naturalnym, co intencjonalnie wykreowanym przez człowieka przy zastosowaniu całej gamy określonych artefaktów ${ }^{26}$.

W antropologicznej i ewolucjonistycznej perspektywie realizacja stanu bezpieczeństwa wiąże się nieodmiennie z koniecznością walki o charakterze zbliżonym do darwinowskiej walki o byt. Jej stawką jest kontynuacja istnienia, ale także jego jakość, którą można określić, zgodnie z definicją zdrowia WHO, jako well-beeing, welness (dobrostan). Walka ta skierowana jest przeciwko licznym zagrożeniom zewnętrznym i wewnętrznym, zarówno fizycznym, jak i psychicznym - jednak jest to już temat na osobny artykuł.

\section{Bibliografia}

Benedict R., Wzory kultury, przeł. J. Prokopiuk, Warszawa 2008.

Brozi K.J., Ludzie i kryzys cywilizacji. Szkice antropologiczne, Lublin 1995.

Burszta W.J., Wprowadzenie do wydania polskiego, [w:] F.C. Sałzman, P.C. Rice, Myśleć jak antropolog, Gdańsk 2009.

Cieślarczyk M., Fenomen bezpieczeństwa i zjawisko kryzysów postrzegane w perspektywie kulturowej, [w:] Jedność i różnorodność. Kultura vs. kultury, red. F. Rekłajtis, R. Wiśniewski, J. Zdanowski, Warszawa 2010.

Cieślarczyk M., Kultura bezpieczeństwa i obronności, Siedlce 2007.

Cieślarczyk M., Teoretyczne i metodologiczne podstawy badania problemów bezpieczeństwa i obronności państwa, Siedlce 2011.

Filipek A., Poziom i charakter kultury bezpieczeństwa młodzieży akademickiej, Siedlce 2007.

Halliday D., Resnick R., Walker J., Podstawy fizyki. t. 3, Warszawa 2003.

Hertz N., Oczy szeroko otwarte, przeł. J. Sawicka, Warszawa 2014.

Hurtado F.A., Ercolani G., Introduction. Anthropology and Security Studies, [w:] Anthropology and Security Studies, red. F.A. Hurtado, G. Ercolani, (USA) 2013.

Jarmoszko S., Antropologia bezpieczeństwa, Siedlce 2018.

Jarmoszko S., Nowe wzory kultury bezpieczeństwa a proces deterioracji więzi społecznej, [w:] Jedność i różnorodność. Kultura vs kultury, red. E. Rekłajtis, R. Wiśniewski, J. Zdanowski, Warszawa 2010.

Kołodziejczyk K., Filozofia bezpieczeństwa. Problemy aksjologiczne, Wrocław 2010.

Reader in Comparative Religion, Anthropological Approach, red. E. Lesa, Z. Vogt, New York.

Linton R., Kulturowe podstawy osobowości, Warszawa 2000.

Maguire V.M., Frois C., Żurawski N., Introduction. The Anthropology of Security: Prospects, Retrospects and Aims, [w:] The Anthropology of Security: Perspectwes front the Frontline of Policing, red. M. Maguire, C. Frois, N. Żurawski, London 2014.

Maurin K., Metody przestrzeni Hilberta, Warszawa 1959.

Munarriz L.A., Foreword. Anthropological Approach to Security, [w:] red. F.A. Hurtado, G. Ercolani, Anthropology and Security Studies, Nottingham 2013 (e-book).

Piwowarski J., Ochrona VIP-a a czworokąt bushido. Studium japońskiej kultury bezpieczeństwa, [w:] Bezpieczeństwo osób podlegających ustawowo ochronie wobec zagrożeń XXI wieku, red. P. Bogdalski, J. Cymerski, K. Jałoszyński, Szczytno 2014.

Rosa R., Filozofia bezpieczeństwa, Warszawa 1995.

${ }^{26}$ S. Jarmoszko, Antropologia bezpieczeństwa..., s. 33.

Forum Socjologiczne 10, 2020

(C) for this edition by CNS 
Szulc B.M., Metodologiczne i epistemologiczne dylematy nauk o bezpieczeństwie i nauk o obronności, [w:] Interdyscyplinarność nauk o bezpieczeństwie. Paradygmat. Wiedza. Demarkacja, red. K. Raczkowski, K. Żukrowska, M. Żuber, Warszawa 2013.

Świniarski J., Chojnacki W., Filozofia bezpieczeństwa. Podręcznik akademicki, Warszawa 2004.

Rosa R., Lipińska-Rzeszutck M., Kubiak M., Filozofia bezpieczeństwa personalnego i strukturalnego, Siedlce 2008.

Tadeusiewicz R., Mity i rzeczywistość społeczeństwa informacyjnego, [w:] Mity współczesnej duchowości, red. Ł. Trzciński, Kraków 2010.

Trejnis Z., Nauki o bezpieczeństwie nowa dyscyplina w dziedzinie nauk społecznych?, „Studia Bezpieczeństwa Narodowego/National Security Studies" 2011.

Williams P.D., Badania bezpieczeństwa. Wprowadzenie, [w:] Studia bezpieczeństwa, red. P.D. Williams, Kraków 2012.

Young S.H., Social Energy, April 2007, http://www.scotthyoung.com/blog/2007/04/10/social-energy.

Zduniak A., Majchrzak N., Świadomość emocjonalna jako dystraktor w procesach badawczych bezpieczeństwa, [w:] Metodologia badań bezpieczeństwa narodowego, t. 3, red. P. Sienkiewicz, M. Marszałek, H. Świeboda, Warszawa 2012.

Zięba R., Kategorie bezpieczeństwa w nauce o stosunkach międzynarodowych, [w:] Bezpieczeństwo narodowe i międzynarodowe u schyłku XX w., Warszawa 1997.

\section{Methodological identity of anthropology of security. Prolegomena}

\section{Summary}

The uniqueness of the humankind as compared to other species living on Earth stems not only from numerous evolutionary conditions, both physical and psychological, but also from the fact that humankind creates broadly understood culture. The fact that anthropology of security shows some connections with culture studies implies that it should incorporate elements related to these studies. An anthropologist of security should mainly focus on the anthropological and cultural aspects of the pursuit of freedom from threats. The same premises of this research field is occupied by security culture. Moreover, anthropology of security is situated at the intersection of two disciplines: anthropology and security sciences. The authors present the dependencies and consequences that the aforementioned facts bring to research on anthropology of security.

Keywords: security culture, anthropology, anthropology of security, security sciences, security 